\title{
Comorbidities associated with nontuberculous mycobacterial disease in Japanese adults: a claims-data analysis
}

Shunsuke Uno ${ }^{1}$, Takanori Asakura ${ }^{2,3}$, Kozo Morimoto ${ }^{4,5}$, Kimio Yoshimura ${ }^{6}$, Yoshifumi Uwamino ${ }^{1,7}$, Tomoyasu Nishimura ${ }^{8}$, Yoshihiko Hoshino ${ }^{3}$, Naoki Hasegawa ${ }^{1 *}$ (D) and Nontuberculous Mycobacteriosis and Bronchiectasis-Japan Research Consortium (NTM-JRC)

\begin{abstract}
Background: Nontuberculous mycobacterial (NTM) lung disease is one of a growing number of chronic health problems that is difficult to cure in aging societies. While it is important to be vigilant about associated comorbidities in order to provide better patient care, data on the prevalence of comorbidities stratified by country or region are scarce. We aimed to elucidate the comorbidities associated with NTM disease based on Japanese health insurance claims data.

Methods: Cross-sectional analyses were performed using the claims data for 2014 provided by the Japan Medical Data Center Co., Ltd. Patients aged 20-75 years with $\geq 3$ claims associated with NTM disease were identified and matched to 10 sex-and-age-matched controls that had never made a claim for NTM disease. Thirty-one comorbidities previously suspected to be associated with NTM disease were selected, and the prevalence of these comorbidities compared between cases and controls.

Result: Overall, 419 NTM patients (134 males and 285 females) and 4190 non-NTM controls were identified from the JMDC database. Aspergillosis, asthma, chronic heart failure, diffuse panbronchiolitis, gastroesophageal reflux, interstitial pneumonia, lung cancer, cancer other than breast, lung, ovary, or prostate cancer, and rheumatoid arthritis were associated with NTM disease in both males and females. Chronic obstructive pulmonary disease was associated with NTM in males while chronic kidney disease, osteoporosis, and Sjögren syndrome were associated with NTM in females.
\end{abstract}

Conclusion: NTM disease was associated with multiple comorbidities that should be considered when providing medical care to individuals with NTM disease.

Keywords: Claims-data analysis, Comorbidities, Nontuberculous mycobacterial diseases

\footnotetext{
* Correspondence: n-hasegawa@z8.keio.jp

'Department of Infectious Diseases, Keio University School of Medicine, 35 Shinanomachi, Shinjuku, Tokyo, Japan

Full list of author information is available at the end of the article
}

(c) The Author(s). 2020 Open Access This article is licensed under a Creative Commons Attribution 4.0 International License, which permits use, sharing, adaptation, distribution and reproduction in any medium or format, as long as you give appropriate credit to the original author(s) and the source, provide a link to the Creative Commons licence, and indicate if changes were made. The images or other third party material in this article are included in the article's Creative Commons licence, unless indicated otherwise in a credit line to the material. If material is not included in the article's Creative Commons licence and your intended use is not permitted by statutory regulation or exceeds the permitted use, you will need to obtain permission directly from the copyright holder. To view a copy of this licence, visit http://creativecommons.org/licenses/by/4.0/ The Creative Commons Public Domain Dedication waiver (http://creativecommons.org/publicdomain/zero/1.0/) applies to the data made available in this article, unless otherwise stated in a credit line to the data. 


\section{Background}

Nontuberculous mycobacterial (NTM) lung disease is one of a growing number of chronic health problems that is difficult to cure. Some patients remain stable without treatment, but others die despite being treated with multidrug combination antimycobacterial chemotherapy. The incidence of NTM lung disease is rapidly increasing worldwide [1], and lifelong antimycobacterial chemotherapy is often required to control the disease.

Patients with chronic NTM disease, regardless of whether they are on treatment or not, are getting older and their quality of life may be lowered [2]. In the Japanese aging society, patients with NTM disease have become older, and prevalence of the NTM disease is higher in older people. Individuals with NTM disease often suffer from other health problems such as malignancies or cardiovascular diseases, and these comorbidities are often the cause of death [3]. It is important to pay attention to comorbidities in the management of NTM disease in order to provide optimal patient care.

Previous retrospective studies have shown that diffuse panbronchiolitis, lung cancer, and rheumatoid arthritis may be associated with NTM disease [4-6]. Populationbased studies have also identified comorbidities such as chronic obstructive pulmonary diseases (COPD), osteoporosis, gastroesophageal reflux (GERD), cystic fibrosis to be associated with NTM disease [7, 8]. Marras et al. [9] analyzed the comorbidities associated with NTM disease using claims data of the United States (US) managed-care population, which included both NTM and non-NTM patients. However, disease prevalence should be analyzed on the basis of the data of each country or region because differences in environmental and genetic factors lead to different comorbidities (e.g., the prevalence of atherosclerosis or cardiovascular disease differs in each country or region) $[10,11]$. In addition, the pathogenic species of Mycobacterium vary by country and region $[8,12]$ and the prevalence of different species may lead to the different clinical picture. Therefore, we conducted claims-data-based analyses to determine the comorbidities associated with NTM disease in Japan.

\section{Methods}

\section{Data source}

Analyses were conducted using claims data provided by the Japan Medical Data Center Co., Ltd. (JMDC). JMDC has contracts with multiple Japanese health insurance societies and has accumulated reimbursement data from more than 3,000,000 individuals. The JMDC database includes only individuals aged $<75$ years because individuals aged $\geq 75$ years are covered by National Health Insurance and membership of the original health insurance society is terminated on reaching the age of 75 years. Personal information is encrypted and claims data are recorded chronologically for each individual under a unique encrypted identifier. The database records information on all medical consultations from all medical institutions and medical care providers. The information about residence of the enrollees are deleted in the database. Seven hundred sixty-nine thousand six hundred twenty-seven individuals who were registered in JMDC in 2014 were employees and 794,669 were dependent family members. Health insurance societies that had contracts with JMDC did not include business owners or welfare recipients.

\section{Study design, patient identification, and matching}

A case-control study was conducted using JMDC data. Individuals with NTM disease were included from 1,564, 296 individuals who were registered in JMDC in 2014. Individuals aged $\geq 20$ years with $\geq 3$ claims associated with NTM disease (International Classification of Diseases, tenth revision [ICD-10] A31.0 [Pulmonary mycobacterial infection] or A31.9 [Msycobacterial infection, unspecified]) on separate occasions $\geq 1$ month apart from January 2014 to December 2014 were identified from the JMDC data. The prevalence of NTM disease in 2014 was calculated. Controls that never had a claim associated with NTM disease were randomly extracted from patients who visited a medical facility at least once in 2014. A total of ten controls were matched by sex and age for each case.

Other comorbidities were identified utilizing ICD-10 codes from medical claims based on $\geq 3$ claims separate occasions $\geq 1$ month apart in 2014 as well (Table 1). Only confirmed diagnoses were included in the analysis. The 30 comorbidity complexes that had previously been suspected as associated with NTM disease were selected and compared [4-9, 13, 14]. The definition of diffuse panbronchiolitis (DPB) also required be on long-term macrolide treatment.

Ethics approval was not applicable to this study based on Ethical Guidelines for Medical and Health Research Involving Human Subject issued by the Japanese Ministry of Health, Labour and Welfare since only completely encrypted data were used.

\section{Statistical analysis}

The proportion of comorbidities among NTM group and non-NTM group was compared by chi-square test. We addressed multiple testing by setting a Bonferroniadjusted significance level of $P$-value $<0.000833$ (0.05/ 60 ) as we tested 30 comorbidity complexes separating sex. All statistical analyses and matching were performed using EZR (Saitama Medical Center, Jichi Medical University, Saitama, Japan), graphical user interface for $R$ 
Table 1 ICD-10 codes for definition of comorbidity complexes

\begin{tabular}{|c|c|}
\hline Comorbidity complexes & ICD-10 codes \\
\hline Arrhythmia & 144.x, 145.x, 147.x, 148.x, 149.x \\
\hline Aspergillosis & B44.x \\
\hline Asthma & J45.x \\
\hline Bone fracture & $\begin{array}{l}\text { M80.x, M84.0, M84.3, M84.4, M96.6, S02.x, } \\
\text { S22.x, S32.x, S42.x, S52.x, S62.x, S72.x, S82.x, } \\
\text { S92.x, T02.x, T08, T14.2, T91.1, T93.2, T94.1 }\end{array}$ \\
\hline Breast cancer & C50.x \\
\hline Chronic heart failure & 111.x, |42.x, 150.x \\
\hline Chronic kidney disease & N18.x, N28.9 \\
\hline COPD & J43.X, J44.9 \\
\hline Crohn's disease & K50.x \\
\hline Depression & F32.x, F33.x \\
\hline Diabetes mellitus & E10.x-E14.X, R73.0 \\
\hline Diffuse panbronchiolitis & J44.8 \\
\hline Dyslipidemia & E78.x \\
\hline GERD & K21.0, K21.9 \\
\hline Heart valve disease & $105 . x-108 . x, 134 . x-137 . x, 138$ \\
\hline HIV infection & B24 \\
\hline Hypertension & $|10| 11 . x,,|12 . x| 15 . x$, \\
\hline Ischemic heart disease & I20.x, I21.x, I24.x, I25.1, I25.2, I25.5, I25.6, I25.9 \\
\hline Interstitial pneumonia & J84.1, J84.9, J70.4 \\
\hline Liver cirrhosis & B18.1, B18.2, K70.3, K74.6 \\
\hline Lung cancer & C34.x \\
\hline Osteoporosis & M80.x, M81.x \\
\hline Other cancer & $\begin{array}{l}\text { C00.x-C26.x, C30.x-C33.x, C37.x-C41.x, } \\
\text { C43.x-C49.x, C51.x-C55.x, C57.x, C58.x, } \\
\text { C60.x, C62.x-C85.x, C88.x, C90.x-C97.x }\end{array}$ \\
\hline Ovary cancer & C56 \\
\hline PM/DM & M33.x \\
\hline Prostate cancer & $\mathrm{C} 61$ \\
\hline Rheumatoid arthritis & M06.9 \\
\hline Sjogren syndrome & M35.0 \\
\hline SLE & M32.1, M32.9 \\
\hline Systemic sclerosis & M34.x \\
\hline
\end{tabular}

(The R Foundation for Statistical Computing, Vienna, Austria).

\section{Results}

A total of 419 NTM patients (134 males and 285 females) were selected from the JMDC database, and 4190 non-NTM controls (1340 males and 2850 females) were identified. The sex and age distribution of the patients is shown in Fig. 1. The median age was 59 years (males 58, females 60$)$; $68 \%$ (285/419) were female. Overall, 1,564,
296 people were registered in JMDC in the year 2014, and the prevalence of NTM diseases in the patients aged 20-75 years old was calculated as $26.8 / 100,000$ population.

The prevalence of comorbidities is shown in Tables 2 and 3. Of the respiratory diseases considered, aspergillosis, asthma, DPB, interstitial pneumonia, and lung cancer were significantly associated with NTM disease in both sex groups. In addition, GERD, other cancer, and rheumatoid arthritis were significantly associated with NTM disease in both sex groups. COPD was also significantly associated with NTM disease in males, while chronic kidney disease (CKD), osteoporosis, and Sjögren syndrome were significantly associated with NTM disease in females. The prevalence of chronic heart failure was significantly associated with NTM disease in the unstratified analysis, but not in the sex-stratified analysis. For patients with DPB, six were on long-term macrolide treatment and one was treated with multidrug antiNTM antibiotics including macrolides.

\section{Discussion}

We conducted a case-control study using JMDC data and investigated the coexistence of NTM disease and comorbid conditions in Japanese adults. JMDC has collected reimbursement data since 2005 and the size of the database makes it valuable resource for estimating the prevalence of diseases. This is the first study evaluating comorbidities associated with NTM disease in Japanese adults based on a case-control analysis using Japanese health insurance claims database. We have newly added comorbidities such as CKD, DPB, osteoporosis, and Sjögren syndrome to previously reported comorbidities in the US claims-data analysis [9]. Human immunodeficiency virus (HIV) and cystic fibrosis are well-known risk factors of NTM disease [15]. However, our data did not contain individuals with these diseases because of their low prevalence in Japan. The calculated prevalence and the proportion of females with NTM disease were similar to those reported in a previous Japanese study [14] of NTM lung disease (NTM-LD). It is likely that the majority of cases in our study had NTMLD despite of definition it in two codes, A31.0 and A31.9, which are used essentially interchangeably in Japan. The database in JMDC was not contain the result of culture or the residence of individuals; therefore, the analyses including those information was unavailable in this study. A strength of this study is that it included 10 sex-and-age-matched non-NTM controls per case. In addition, we performed Bonferroni-adjustment to resolve the problem of multiple hypothesis testing.

Respiratory diseases and a variety of systemic conditions are comorbid with NTM disease. In terms of respiratory diseases, Marras et al. [9, 16] found an 


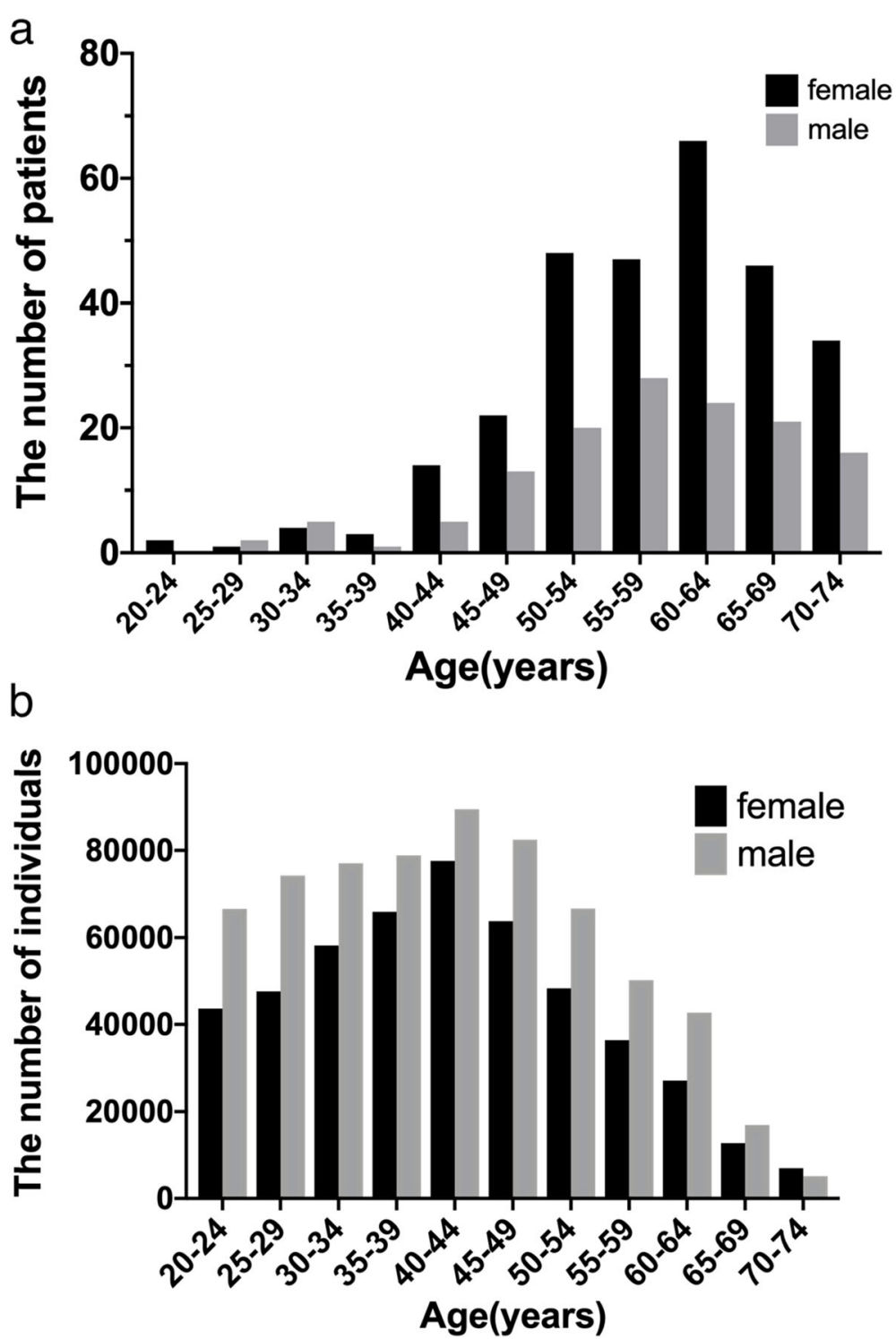

Fig. 1 a The distribution of the patients with NTM disease by sex and age. $\mathbf{b}$ The distribution of entire individuals who were registered in JMDC's database in 2014

association between NTM disease and aspergillosis, asthma, COPD, lung cancer, and tuberculosis in the US claims-data analysis. Our data showed that interstitial lung disease and asthma were comorbid with NTM disease in addition to the classical risk factors such as COPD. A Korean study with 810 NTM-LD patients revealed that 42 patients (5.2\%) had interstitial lung disease, which is a similar proportion to that found in our study [17]. Asthma and COPD, especially if treated with inhaled corticosteroid therapy, and the use of systemic immunosuppressive agents have previously been identified as strongly associated with NTM-LD $[8,9,18,19]$, which might also contribute to the development of NTM-LD in individuals with interstitial lung disease.
Tsuji et al. [4] conducted a retrospective study of 33 patients with diffuse panbronchiolitis (DPB) and found that $7(21.2 \%)$ of the patients also had pulmonary NTM disease. In our analysis, $1.9 \%$ of patients with NTM disease also had DPB. This fact is more characteristic in Japanese or Asian patients than it is among individuals in the US or Europe because DPB mainly affects East Asian people [20]. We speculated that DPB is a risk factor for NTM disease, but does not occur due to NTM disease. Mycobacterium spp. also easily colonize the respiratory tract of DPB patients because DPB is accompanied mucociliary dysfunction and various bacteria colonize the respiratory epithelium [4]. NTM is a wellrecognized pathogen in cystic fibrosis patients [21, 22]. 
Table 2 NTM disease and Comorbidity complexes

\begin{tabular}{|c|c|c|c|c|}
\hline Comorbidity complexes & $\begin{array}{l}\text { NTM(N=419) } \\
\mathrm{n}(\%)\end{array}$ & $\begin{array}{l}\text { non-NTM }(N=4190) \\
\text { n (\%) }\end{array}$ & Odds ratio $[95 \% \mathrm{Cl}]$ & $P$ value \\
\hline Arrhythmia & $28(6.68)$ & $176(4.20)$ & $1.63[1.04-2.48]$ & 0.0243 \\
\hline Aspergillosis & $8(1.90)$ & $0(0)$ & $+\infty[17.3-+\infty]$ & $<0.0001^{*}$ \\
\hline Asthma & $77(18.3)$ & $194(4.63)$ & $4.63[3.43-6.21]$ & $<0.0001^{*}$ \\
\hline Bone fracture & $13(3.10)$ & $64(1.52)$ & $2.06[1.03-3.83]$ & 0.0255 \\
\hline Breast cancer & $4(0.954)$ & $43(1.02)$ & $0.93[0.24-2.58]$ & $>0.99$ \\
\hline Chronic heart failure & $31(7.39)$ & $130(3.10)$ & $2.49[1.61-3.77]$ & $<0.0001^{*}$ \\
\hline Chronic kidney disease & $16(3.81)$ & $54(1.28)$ & $3.04[1.61-5.45]$ & $0.000403^{*}$ \\
\hline COPD & $13(3.10)$ & $22(0.525)$ & $6.06[2.78-12.69]$ & $<0.0001^{*}$ \\
\hline Crohn's disease & $2(0.477)$ & $0(0)$ & $+\infty[1.88-+\infty]$ & 0.00825 \\
\hline Depression & $16(3.81)$ & $107(2.55)$ & $1.51[0.83-2.61]$ & 0.149 \\
\hline Diabetes mellitus & $62(14.7)$ & $608(14.5)$ & $1.02[0.76-1.36]$ & 0.884 \\
\hline Diffuse panbronchiolitis & $7(1.67)$ & $0(0)$ & $+\infty[14.57-+\infty]$ & $<0.0001^{*}$ \\
\hline Dyslipidemia & $105(25.0)$ & $1110(26.4)$ & $0.93[0.73-1.17]$ & 0.561 \\
\hline GERD & $83(19.8)$ & $355(8.47)$ & $2.67[2.02-3.49]$ & $<0.0001^{*}$ \\
\hline Heart valve disease & $11(2.62)$ & $54(1.28)$ & $2.06[0.97-4.03]$ & 0.0455 \\
\hline HIV infection & $0(0)$ & $0(0)$ & NA & NA \\
\hline Hypertension & $110(26.2)$ & $1166(27.8)$ & $0.92[0.73-1.16]$ & 0.529 \\
\hline Ischemic heart disease & $29(6.92)$ & $191(4.55)$ & $1.56[1.00-2.35]$ & 0.04 \\
\hline Interstitial pneumonia & $25(5.96)$ & $14(0.334)$ & 18.89 [9.36-39.70] & $<0.0001^{*}$ \\
\hline Liver cirrhosis & $4(0.954)$ & $25(0.596)$ & $1.61[0.40-4.68]$ & 0.33 \\
\hline Lung cancer & $19(4.53)$ & $13(0.310)$ & 15.24 [7.08-33.86] & $<0.0001^{*}$ \\
\hline Osteoporosis & $46(10.9)$ & $220(5.25)$ & 2.23 [1.56-3.13] & $<0.0001^{*}$ \\
\hline Other cancer & $41(9.78)$ & $117(2.79)$ & $3.77[2.54-5.52]$ & $<0.0001^{*}$ \\
\hline Ovary cancer & $1(0.238)$ & $8(0.190)$ & $1.25[0.028-9.37]$ & 0.576 \\
\hline PM/DM & $1(0.238)$ & $2(0.0477)$ & 5.01 [0.085-96.47] & 0.249 \\
\hline Prostate cancer & $0(0)$ & $15(0.357)$ & $0[0-2.79]$ & 0.389 \\
\hline Rheumatoid arthritis & $23(5.48)$ & $66(1.57)$ & 3.63 [2.13-5.99] & $<0.0001^{*}$ \\
\hline Sjögren syndrome & $10(2.38)$ & $13(0.310)$ & 7.85 [3.06-19.50] & $<0.0001^{*}$ \\
\hline SLE & $3(0.715)$ & $7(0.167)$ & $4.31[0.72-18.95]$ & 0.0552 \\
\hline Systemic sclerosis & $4(0.954)$ & $3(0.0715)$ & 13.44 [2.26-91.95] & 0.00189 \\
\hline
\end{tabular}

COPD Chronic obstructive pulmonary diseases, GERD Gastroesophageal reflux, HIV Human immunodeficiency virus, PM/DM Polymyositis/dermatomyositis, SLE Systemic lupus erythematosus, * statistically different, NA Not applicable

However, the prevalence of cystic fibrosis in Japan is very limited, and there were no patients with cystic fibrosis in our data.

Kusumoto et al. [5] pointed out the high incidence of lung cancer in patients with NTM-LD, with an estimated incidence rate of 124.6 per 100,000 patient-years. This incidence is much higher than that reported in Japan. These association between NTM diseases and lung cancer could be a detection bias, as patients with NTM-LD have chest CT scans more frequently than healthy individuals and are therefore more likely to have other lung nodules discovered incidentally. Kusumoto et al. also speculated that chronic lung inflammation might cause lung cancer, however, the pathogenesis of lung cancer in relation to NTM disease is unknown [5].

In terms of non-pulmonary comorbidities, patients with NTM had a significantly higher prevalence of chronic heart failure, GERD, cancer other than breast, lung, ovary, or prostate cancer, and rheumatoid arthritis than controls in both males and females. Females with NTM disease also had a significantly higher prevalence of CKD, osteoporosis, and Sjögren syndrome than controls. The coexistence between NTM disease and chronic heart failure, GERD, other cancer, and rheumatoid arthritis has been reported previously $[8,9,16]$. Chao et al. [23] reported an increased risk of NTM 
Table 3 NTM disease and Comorbidity complexes analyzed separating sexes

\begin{tabular}{|c|c|c|c|c|c|c|c|c|}
\hline \multirow[b]{2}{*}{ Comorbidity complexes } & \multicolumn{4}{|c|}{ Male $N=1474$} & \multicolumn{4}{|c|}{ Female $N=3135$} \\
\hline & $\begin{array}{l}\text { NTM, } \\
N=134\end{array}$ & $\begin{array}{l}\text { non-NTM, } \\
N=1340\end{array}$ & $\begin{array}{l}\text { Odds ratio } \\
{[95 \% \mathrm{Cl}]}\end{array}$ & $P$ value & $\begin{array}{l}\text { NTM, } \\
N=285\end{array}$ & $\begin{array}{l}\text { non-NTM, } \\
N=2850\end{array}$ & $\begin{array}{l}\text { Odds ratio } \\
{[95 \% \mathrm{Cl}]}\end{array}$ & $P$ value \\
\hline Arrhythmia & $15(11.19)$ & $71(5.29)$ & $2.25[1.16-4.12]$ & 0.0105 & $13(4.56)$ & $105(3.68)$ & $1.25[0.64-2.27]$ & 0.417 \\
\hline Aspergillosis & $5(3.73)$ & $0(0)$ & $+\infty[9.36-+\infty]$ & $<0.0001^{*}$ & $3(1.05)$ & $0(0)$ & $+\infty[4.15-+\infty]$ & $0.000744^{*}$ \\
\hline Asthma & $30(22.3)$ & $60(4.47)$ & $6.14[3.65-10.17]$ & $<0.0001^{*}$ & $47(16.4)$ & $134(4.70)$ & $4.00[2.73-5.78]$ & $<0.0001^{*}$ \\
\hline Bone fracture & $3(2.23)$ & $8(0.597)$ & $3.81[0.64-16.11]$ & 0.0705 & $10(3.50)$ & $56(1.96)$ & $1.81[0.82-3.64]$ & 0.0854 \\
\hline Breast cancer & $0(0)$ & $1(0.0746)$ & $0[0-387.6]$ & $>0.99$ & $4(1.40)$ & $42(1.47)$ & $0.95[0.25-2.65]$ & $>0.99$ \\
\hline Chronic heart failure & $11(8.20)$ & $43(3.20)$ & $2.69[1.22-5.49]$ & 0.00731 & $20(7.01)$ & $87(3.05)$ & $2.40[1.37-4.01]$ & 0.00158 \\
\hline Chronic kidney disease & $5(3.73)$ & $25(1.86)$ & $2.04[0.60-5.54]$ & 0.185 & $11(3.85)$ & $29(1.01)$ & $3.90[1.74-8.16]$ & $0.000605^{*}$ \\
\hline COPD & $9(6.71)$ & $11(0.820)$ & $8.67[3.11-23.51]$ & $<0.0001^{*}$ & $4(1.40)$ & $11(0.385)$ & $3.67[0.85-12.49]$ & 0.0408 \\
\hline Crohn's disease & $2(1.49)$ & $0(0)$ & $+\infty[1.89-+\infty]$ & 0.0821 & $0(0)$ & $0(0)$ & NA & NA \\
\hline Depression & $2(1.49)$ & $32(2.38)$ & $0.62[0.071-2.48]$ & 0.763 & $14(4.91)$ & $75(2.63)$ & $1.91[0.98-3.47]$ & 0.0374 \\
\hline Diabetes mellitus & $28(20.89)$ & $241(17.98)$ & $1.20[0.75-1.89]$ & 0.412 & $34(11.9)$ & $367(12.8)$ & $0.92[0.61-1.34]$ & 0.71 \\
\hline Diffuse panbronchiolitis & $4(2.98)$ & $0(0)$ & $+\infty[6.70-+\infty]$ & $<0.0001^{*}$ & $3(1.05)$ & $0(0)$ & $+\infty[4.15-+\infty]$ & $0.000744^{*}$ \\
\hline Dyslipidemia & $26(19.4)$ & $345(25.7)$ & $0.69[0.43-1.10]$ & 0.118 & $79(27.7)$ & $765(26.8)$ & $1.05[0.79-1.38]$ & 0.779 \\
\hline GERD & $35(26.1)$ & $118(8.80)$ & $3.66[2.31-5.71]$ & $<0.0001^{*}$ & $48(16.8)$ & $237(8.31)$ & $2.23[1.56-3.15]$ & $<0.0001^{*}$ \\
\hline Heart valve disease & $6(4.47)$ & $17(1.26)$ & 3.64 [1.16-9.90] & 0.0139 & $5(1.75)$ & $37(1.29)$ & $1.36[0.41-3.50]$ & 0.427 \\
\hline HIV infection & $0(0)$ & $0(0)$ & NA & NA & $0(0)$ & $0(0)$ & NA & NA \\
\hline Hypertension & $40(29.8)$ & $432(32.2)$ & 0.89 [0.59-1.33] & 0.628 & $70(24.5)$ & $734(25.7)$ & $0.94[0.70-1.25]$ & 0.722 \\
\hline Ischemic heart disease & $14(10.4)$ & $75(5.59)$ & $1.97[1.00-3.64]$ & 0.0344 & $15(5.26)$ & $116(4.07)$ & $1.31[0.70-2.29]$ & 0.35 \\
\hline Interstitial pneumonia & $12(8.95)$ & $4(0.298)$ & $32.66[9.71-141.0]$ & $<0.0001^{*}$ & $13(4.56)$ & $10(0.350)$ & 13.55 [5.43-34.89] & $<0.0001^{*}$ \\
\hline Liver cirrhosis & $3(2.23)$ & $3(0.223)$ & $10.17[1.35-76.71]$ & 0.012 & $1(0.350)$ & $22(0.771)$ & $0.45[0.011-2.82]$ & 0.716 \\
\hline Lung cancer & $10(7.46)$ & $8(0.597)$ & $13.37[4.66-39.77]$ & $<0.0001^{*}$ & $9(3.15)$ & $5(0.175)$ & 18.52 [5.53-70.69] & $<0.0001^{*}$ \\
\hline Osteoporosis & $4(2.98)$ & $10(7.46)$ & $4.09[0.92-14.42]$ & 0.0318 & $42(14.7)$ & $210(7.36)$ & $2.17[1.48-3.13]$ & $<0.0001^{*}$ \\
\hline Other cancer & $18(13.4)$ & $45(3.35)$ & $4.46[2.35-8.16]$ & $<0.0001^{*}$ & $23(8.07)$ & $72(2.52)$ & 3.39 [1.98-5.59] & $<0.0001^{*}$ \\
\hline Ovary cancer & $0(0)$ & $0(0)$ & NA & NA & $1(0.35)$ & $8(0.280)$ & 1.25 [0.028-9.39] & 0.576 \\
\hline PM/DM & $0(0)$ & $0(0)$ & NA & NA & $1(0.35)$ & $2(0.0701)$ & 5.01 [0.085-96.61] & 0.249 \\
\hline Prostate cancer & $0(0)$ & $15(1.11)$ & $0[0-2.79]$ & 0.387 & $0(0)$ & $0(0)$ & NA & NA \\
\hline Rheumatoid arthritis & $6(4.47)$ & $5(0.373)$ & $12.47[3.12-52.32]$ & $0.00016^{*}$ & $17(5.96)$ & $61(2.14)$ & $2.90[1.56-5.12]$ & $0.000458^{*}$ \\
\hline Sjögren syndrome & $0(0)$ & $0(0)$ & NA & NA & $10(3.50)$ & $13(0.456)$ & 7.92 [3.08-19.76] & $<0.0001^{*}$ \\
\hline SLE & $0(0)$ & $1(0.0746)$ & $0[0-387.6]$ & $>0.99$ & $3(1.05)$ & $6(0.210)$ & $5.04[0.81-23.74]$ & 0.0413 \\
\hline Systemic sclerosis & $1(0.746)$ & $1(0.0746)$ & $10.03[0.13-785.3]$ & 0.174 & $3(1.05)$ & $2(0.0701)$ & 15.11 [1.72-181.5] & 0.0647 \\
\hline
\end{tabular}

COPD Chronic obstructive pulmonary diseases, GERD Gastroesophageal reflux, HIV Human immunodeficiency virus, PM/DM Polymyositis/dermatomyositis, SLE Systemic lupus erythematosus, *statistically different, NA Not applicable

disease in patients with Sjögren syndrome based on an analysis of Taiwan's National Health Insurance Research Database analysis. Pulmonary abnormalities have been described as an extra-glandular involvement of Sjögren syndrome [24]. NTM-LD may be an underlying condition in patients with Sjögren syndrome because some patients with Sjögren syndrome have been reported to develop bronchiectasis $[25,26]$, and pulmonary involvement in patients with Sjögren syndrome can be difficult to distinguish from NTM-LD using CT.

Menopause is a well-known risk factor for NTM disease [27], and osteoporosis also frequently occur in those population. Low serum estradiol had been related to development of NTM-LD [28], and it might be a confounding factor between osteoporosis and NTM diseases. In addition, Jeon et al. [13] reported the association between severe vitamin D deficiency and development of NTM disease; thus, vitamin D deficiency may also be a confounding factor of these diseases. Measurement of serum vitamin D level was not supported by the health insurance system in Japan in 2014, so we were unable to assess whether there was an association between vitamin D deficiency and NTM disease. COPD, a common chronic pulmonary disease, has been reported 
to be an independent risk factor of osteoporosis [29] and so there is a need to investigate the mechanism of development of osteoporosis in patients with NTM disease.

This study should be interpreted in light of several limitations. First, the analysis was based on data from a claims database. Since we did not have access to the clinical or microbiological information of the participants, the prevalence of some disease complexes might differ from that based on a true diagnosis and it needs to be interpreted with caution and would be preferred to be validated by clinical study. Previous researchers have defined their targeted diseases by $\geq 2$ claims in several claims-data analyses $[9,16,30-33]$; however, we defined by $\geq 3$ claims to increase the specificity. Our more stringent definition of comorbidities may have led to a bias toward the null, making it less likely to detect true associations. However, this feature of our study likely ensured that the detected associations were accurate and robust. This issue is further strengthened by the use of Bonferroni correction for multiple comparisons. The calculated prevalence and proportion of women were similar to that reported in the previous study [14]; thus, the accuracy of our diagnosis of NTM disease is likely to be comparable to that of previous studies. Second, we were unable to differentiate the Mycobacterium species due to unavailability of microbiological information. Third, JMDC database did not include patients aged $\geq 75$ years belonging to National Health Insurance. Thus, the result should be interpreted as people $<75$ years of age and the association of older patients could differ. It would be ideal to have included patients aged $\geq 75$ years as comorbidities increases with advanced age. In addition, there is another selection bias of JMDC database including only employee and their dependent family members and not including business owners or welfare recipients. Fourth, it should be interpreted to be careful to the differences with clinical significance in such a big data analysis instead of performance of Bonferroni-adjusted analysis. In addition, the prevalence of aspergillosis or DPB are 0 in non-NTM group; thus, it should be validated with larger datasets.

\section{Conclusion}

we elucidated the comorbidities complex associated with NTM disease in Japanese adults based on a claims-data analysis. Clinicians should be aware of these specific comorbidities when providing medical care for patients with NTM disease.

\section{Abbreviations}

CKD: Chronic kidney disease; COPD: Chronic obstructive pulmonary diseases; CT: Computed tomography; DPB: Diffuse panbronchiolitis;

GERD: Gastroesophageal reflux; HIV: Human immunodeficiency virus; ICD10: International Classification of Diseases, tenth revision; JMDC: Japan Medical Data Center Co., Ltd.; NTM: Non-tuberculous Mycobacterium; NTM-
LD: Non-tuberculous Mycobacterium lung disease; PM/DM: Polymyositis/ dermatomyositis; SLE: Systemic lupus erythematosus; US: United States

\section{Acknowledgements}

Not applicable.

\section{Authors' contributions}

SU designed the study, analyzed, and drafted the manuscript; TA and KM designed the study and participated in editing the manuscript; KY confirmed the analyses, and revised the article for intellectual content; YU and TN conceptualized the study and revised the article for intellectual content; $\mathrm{YH}$ conceptualized the study, supervised, and acquired funding; $\mathrm{NH}$ participated in editing the manuscript, acquired funding, and revised the article for intellectual content. All authors read and critically revised the first as well as the subsequent and final drafts of this manuscript. The author(s) read and approved the final manuscript.

\section{Funding}

This work was in part supported by a grant from the Japan Agency for Medical Research and Development/Japan International Cooperation Agency (AMED) (jp18fk0108064). The funders had no role in study design, data collection and analysis, decision to publish, or preparation of the manuscript.

Availability of data and materials

The datasets used and analyzed during the current study are available from the corresponding author on reasonable request.

Ethics approval and consent to participate

Ethics approval was not applicable to this study based on Ethical Guidelines for Medical and Health Research Involving Human Subject issued by the Japanese Ministry of Health, Labour and Welfare since only completely encrypted data were used.

Consent for publication

Not applicable.

Competing interests

None.

\section{Author details}

${ }^{1}$ Department of Infectious Diseases, Keio University School of Medicine, 35 Shinanomachi, Shinjuku, Tokyo, Japan. ${ }^{2}$ Division of Pulmonary Medicine, Department of Medicine, Keio University School of Medicine, Tokyo, Japan. ${ }^{3}$ Department of Mycobacteriology, Leprosy Research Center, National Institute of Infectious Diseases, Tokyo, Japan. ${ }^{4}$ The Research Institute of Tuberculosis, Japan Anti-Tuberculosis Association, Tokyo, Japan. ${ }^{5}$ Division of Clinical Research, Fukujuji Hospital, Japan Anti-Tuberculosis Association, Tokyo, Japan. ${ }^{6}$ Department of Health Policy and Management, Keio University School of Medicine, Tokyo, Japan. ${ }^{7}$ Department of Laboratory medicine, Keio University School of Medicine, Tokyo, Japan. ${ }^{8}$ Keio University Health Center, Tokyo, Japan.

Received: 13 April 2020 Accepted: 29 September 2020

Published online: 09 October 2020

\section{References}

1. Namkoong H, Kurashima A, Morimoto K, Hoshino Y, Hasegawa N, Ato M, et al. Epidemiology of pulmonary nontuberculous mycobacterial disease, Japan (1). Emerg Infect Dis. 2016;22(6):1116-7.

2. Asakura T, Funatsu $Y$, Ishii M, Namkoong H, Yagi $K$, Suzuki S, et al. Healthrelated quality of life is inversely correlated with $C$-reactive protein and age in Mycobacterium avium complex lung disease: a cross-sectional analysis of 235 patients. Respir Res. 2015;16:145.

3. Diel R, Lipman M, Hoefsloot W. High mortality in patients with Mycobacterium avium complex lung disease: a systematic review. BMC Infect Dis. 2018;18(1):206

4. Tsuji T, Tanaka E, Yasuda I, Nakatsuka Y, Kaji Y, Yasuda T, et al. Nontuberculous mycobacteria in diffuse panbronchiolitis. Respirology. 2015: 20(1):80-6. 
5. Kusumoto T, Asakura T, Suzuki S, Okamori S, Namkoong H, Fujiwara H, et al. Development of lung cancer in patients with nontuberculous mycobacterial lung disease. Respir Investig. 2019;57(2):157-64.

6. Liao TL, Lin CH, Shen GH, Chang CL, Lin CF, Chen DY. Risk for mycobacterial disease among patients with rheumatoid arthritis, Taiwan, 2001-2011. Emerg Infect Dis. 2015;21(8):1387-95.

7. Ringshausen FC, Wagner D, de Roux A, Diel R, Hohmann D, Hickstein L, et al. Prevalence of Nontuberculous mycobacterial pulmonary disease, Germany, 2009-2014. Emerg Infect Dis. 2016;22(6):1102-5.

8. Prevots DR, Marras TK. Epidemiology of human pulmonary infection with nontuberculous mycobacteria: a review. Clin Chest Med. 2015;36(1):13-34.

9. Marras TK, Vinnard C, Zhang Q, Hamilton K, Adjemian J, Eagle G, et al. Relative risk of all-cause mortality in patients with nontuberculous mycobacterial lung disease in a US managed care population. Respir Med. 2018:145:80-8

10. Sekikawa A, Ueshima H, Kadowaki T, El-Saed A, Okamura T, Takamiya T, et al. Less subclinical atherosclerosis in Japanese men in Japan than in white men in the United States in the post-world war II birth cohort. Am J Epidemiol. 2007;165(6):617-24.

11. Abbott RD, Ueshima H, Rodriguez BL, Kadowaki T, Masaki KH, Willcox BJ, et al. Coronary artery calcification in Japanese men in Japan and Hawaii. Am J Epidemiol. 2007;166(11):1280-7.

12. Hoefsloot W, van Ingen J, Andrejak C, Angeby K, Bauriaud R, Bemer P, et al. The geographic diversity of nontuberculous mycobacteria isolated from pulmonary samples: an NTM-NET collaborative study. Eur Respir J. 2013; 42(6):1604-13

13. Jeon K, Kim SY, Jeong BH, Chang B, Shin SJ, Koh WJ. Severe vitamin D deficiency is associated with non-tuberculous mycobacterial lung disease: a case-control study. Respirology. 2013;18(6):983-8.

14. Izumi K, Morimoto K, Hasegawa N, Uchimura K, Kawatsu L, Ato M, et al. Epidemiology of adults and children treated for Nontuberculous mycobacterial pulmonary disease in Japan. Ann Am Thorac Soc. 2019;16(3): $341-7$.

15. Lake MA, Ambrose LR, Lipman MC, Lowe DM. "Why me, why now?" using clinical immunology and epidemiology to explain who gets nontuberculous mycobacterial infection. BMC Med. 2016;14:54.

16. Marras TK, Mirsaeidi M, Chou E, Eagle G, Zhang R, Leuchars M, et al. Health care utilization and expenditures following diagnosis of Nontuberculous mycobacterial lung disease in the United States. J Manag Care Spec Pharm. 2018;24(10):964-74.

17. Hwang HJ, Kim MY, Shim TS, Kim DS. Nontuberculous mycobacterial pulmonary infection in patients with idiopathic interstitial pneumonias: comparison with patients without idiopathic interstitial pneumonias. J Comput Assist Tomogr. 2014;38(6):972-8.

18. Andrejak C, Nielsen R, Thomsen VO, Duhaut P, Sorensen HT, Thomsen RW. Chronic respiratory disease, inhaled corticosteroids and risk of nontuberculous mycobacteriosis. Thorax. 2013;68(3):256-62.

19. Brode SK, Campitelli MA, Kwong JC, Lu H, Marchand-Austin A, Gershon AS, et al. The risk of mycobacterial infections associated with inhaled corticosteroid use. Eur Respir J. 2017;50(3):1700037.

20. Kudoh S, Keicho N. Diffuse panbronchiolitis. Clin Chest Med. 2012:33(2):297305.

21. Qvist T, Pressler T, Hoiby N, Katzenstein TL. Shifting paradigms of nontuberculous mycobacteria in cystic fibrosis. Respir Res. 2014;15:41.

22. Bar-On O, Mussaffi H, Mei-Zahav M, Prais D, Steuer G, Stafler P, et al. Increasing nontuberculous mycobacteria infection in cystic fibrosis. J Cyst Fibros. 2015;14(1):53-62.

23. Chao WC, Lin CH, Liao TL, Chen YM, Hsu CY, Chen JP, et al. The risk of nontuberculous mycobacterial infection in patients with Sjogren's syndrome: a nationwide, population-based cohort study. BMC Infect Dis. 2017;17(1):796

24. Natalini JG, Johr C, Kreider M. Pulmonary involvement in Sjogren syndrome. Clin Chest Med. 2019;40(3):531-44.

25. Dong X, Zhou J, Guo X, Li Y, Xu Y, Fu Q, et al. A retrospective analysis of distinguishing features of chest HRCT and clinical manifestation in primary Sjogren's syndrome-related interstitial lung disease in a Chinese population. Clin Rheumatol. 2018;37(11):2981-8.

26. Mandl T, Diaz S, Ekberg O, Hesselstrand R, Piitulainen E, Wollmer P, et al. Frequent development of chronic obstructive pulmonary disease in primary SS--results of a longitudinal follow-up. Rheumatology (Oxford). 2012;51(5): 941-6.
27. Prince DS, Peterson DD, Steiner RM, Gottlieb JE, Scott R, Israel HL, et al. Infection with Mycobacterium avium complex in patients without predisposing conditions. N Engl J Med. 1989;321(13):863-8.

28. Uwamino Y, Nishimura T, Sato Y, Tamizu E, Asakura T, Uno S, et al. Low serum estradiol levels are related to Mycobacterium avium complex lung disease: a cross-sectional study. BMC Infect Dis. 2019;19(1):1055.

29. Adas-Okuma MG, Maeda SS, Gazzotti MR, Roco CM, Pradella CO, Nascimento OA, et al. COPD as an independent risk factor for osteoporosis and fractures. Osteoporos Int. Osteoporos Int. 2020;31(4):687-97.

30. Lin WY, Lin MS, Weng YH, Yeh TH, Lin YS, Fong PY, et al. Association of Antiviral Therapy with Risk of Parkinson disease in patients with chronic hepatitis C virus infection. JAMA Neurol. 2019;76(9):1019-27.

31. Yamazaki K, Macaulay D, Song Y, Sanchez Gonzalez Y. Clinical and economic burden of patients with chronic hepatitis $C$ with versus without antiviral treatment in Japan: an observational cohort study using hospital claims data. Infect Dis Ther. 2019;8(2):285-99.

32. Saeed MJ, Olsen MA, Powderly WG, Presti RM. Diabetes mellitus is associated with higher risk of developing decompensated cirrhosis in chronic hepatitis C patients. J Clin Gastroenterol. 2017;51 (1):70-6.

33. Klabunde CN, Potosky AL, Legler JM, Warren JL. Development of a comorbidity index using physician claims data. J Clin Epidemiol. 2000;53(12): 1258-67.

\section{Publisher's Note}

Springer Nature remains neutral with regard to jurisdictional claims in published maps and institutional affiliations.
Ready to submit your research? Choose BMC and benefit from:

- fast, convenient online submission

- thorough peer review by experienced researchers in your field

- rapid publication on acceptance

- support for research data, including large and complex data types

- gold Open Access which fosters wider collaboration and increased citations

- maximum visibility for your research: over $100 \mathrm{M}$ website views per year

At BMC, research is always in progress.

Learn more biomedcentral.com/submissions 